Vliet, L. van, Francke, A., Tomson, S., Plum, N., Wall, E. van der, Bensing, J. When cure is no option: how explicit and hopeful can information be given? A qualitative study in breast cancer. Patient Education and Counseling: 2013, 90(3), 315-322

\begin{tabular}{|l|l|}
\hline Postprint Version & 1.0 \\
\hline Journal website & http://www.sciencedirect.com/science/article/pii/S073839911100187X \\
\hline Pubmed link & http://www.ncbi.nlm.nih.gov/pubmed/21555199 \\
\hline DOI & $10.1016 /$ j.pec.2011.03.021 \\
\hline
\end{tabular}

This is a NIVEL certified Post Print, more info at http://www.nivel.eu

\title{
When cure is no option: How explicit and hopeful can information be given? A qualitative study in breast cancer
}

\author{
LIESBETH VAN VLIET ${ }^{\mathrm{A}}$, , ANNEKE FRANCKE ${ }^{\mathrm{A}}$, ${ }^{\mathrm{B}}$, SAMANTA TOMSON ${ }^{\mathrm{A}}$, NICOLE PLUM ${ }^{\mathrm{C}}$, ELSKEN VAN DER \\ WALL $^{\mathrm{C}}$ AND JOZIEN BENSING ${ }^{\mathrm{A}}{ }^{\mathrm{D}}$ \\ ${ }^{a}$ NIVEL (Netherlands Institute for Health Services Research), Utrecht, The Netherlands \\ ${ }^{\mathrm{b}}$ VU University Medical Center/EMGO+, Amsterdam, The Netherlands \\ ${ }^{c}$ University Medical Center Utrecht, Utrecht University, Utrecht, The Netherlands \\ ${ }^{\mathrm{d}}$ Faculty of Social and Behavioral Science, Utrecht University, Utrecht, The Netherlands
}

\begin{abstract}
Objective: To investigate how oncologists can balance explicit with general and realistic with hopeful information when discussing various topics at the transition from curative to palliative care in breast cancer.

Methods: Qualitative analysis of focus groups consisting of female breast cancer survivors and healthy women.

Results: Perceptions of survivors and healthy women largely overlapped. Participants thought that oncologists can help patients regain a future perspective during this consultation. To achieve this, four themes seemed important: honest medical information, availability of continued support, hope has many faces, and space to choose. Moreover, participants stressed they would need time to let the message sink in before any further information was provided.

Conclusion: Participants thought that when confronted with this type of consultation they would need - more or less explicit - medical information and information regarding support. In order to maintain hope, knowledge about (treatment) possibilities is important, but also the certainty not to be abandoned by the hospital at a later stage of the disease and the confidence to remain able to make one's own decisions.

Practice implications: A life-limiting diagnosis may shatter patients' future perspective; however, this study provides suggestions for oncologists to create a new perspective.
\end{abstract}

\section{INTRODUCTION}

Consultations in which a life-limiting diagnosis is discussed often cause distress to both patients [1], [2] and [3] and oncologists [4], [5] and [6]. Therefore, guidelines have been developed for breaking bad news [7], [8], [9], [10], [11], [12], [13], [14] and [15]. Although there is an increasing focus on patients' perceived needs, these guidelines are usually created by experts [16], [17], [18] and [19]. Providing oncologists with lay people's recommendations for easing the transition from curative to palliative care may improve oncologists' communicative behavior and patients' psychological functioning [20].

\subsection{Explicit versus general information}

Studies focusing on the kind of information patients in the palliative phase prefer indicate that patients need to be aware of the incurable nature of their disease [18], [21], [22], [23] and [24], to handle [25] and [26] and plan their future [27]. Additionally, they require an overview of available palliative treatment 
options [18], [21], [23], [28], [29] and [30] and information on how the cancer will affect their daily life [28], [30] and [31]. However, patients might differ in the preferred time of discussing various topics [32].

Research findings are inconsistent as to how this diagnosis should be discussed and accompanied by information about future expectations [24], [27], [32], [33] and [34] J.M. Clayton, P.N. Butow, R.M. Arnold and M.H. Tattersall, Discussing life expectancy with terminally ill cancer patients and their carers: a qualitative study, Support Care Cancer 13 (2005), pp. 733-742. Full Text via CrossRef | View Record in Scopus | Cited By in Scopus (12)[34]. Most patients want to receive as much information as possible [24], [30], [31], [35], [36] and [37]. However, it is also common to hear patients say they do not wish to receive too much information [38], [39], [40], [41], [42] and [43] or that they are overwhelmed by the information provided [39] and [44]. When exploring this apparent paradox, it seems a substantial minority of cancer patients prefer to remain partly ignorant about their life expectancy [21], [35], [45], [46] and [47]. It is unclear whether numerical data or qualitative words are preferred when discussing future expectations [21], [27], [38] and [45]. Some studies concluded that oncologists should provide patients with as much detailed information as patients prefer but did not specify how much [3], [38] and [48]. Accordingly, recommendations are lacking for oncologists on the level of preferred explicitness when discussing future expectations [49]; so far, no research has explored whether explicit (detailed/specific) information is more often preferred for some topics than for others.

\subsection{Hope versus realism}

Most patients [30], [37], [47] and [48] (and guidelines [19] and [24]) favor ending a bad news conversation with hopeful statements. Patients often express an ongoing need for hope, even against all odds [24], [33], [39], [47], [50], [51], [52] and [53]. At the same time patients often hope for realistic goals such as optimal comfort in the remaining time [51], [53] and [54]. Still, a clear definition of hope is lacking [53] and the content of hope may be subject to change [55].

In a seemingly contradictory fashion, patients (and guidelines) also stress the importance of receiving realistic information [9], [16], [22], [28] and [30]. For some, realistic information may nurture hope [30] and [56] while others argue that realistic information destroys hope [57]. One study found that optimistic statements did not distort patients' prognostic awareness, provided realistic information was also given [52]. Interestingly, patients sometimes simultaneously ask for ambigious, hopeful information and realistic, honest information [39] and [58]. So, while the literature stresses that oncologists should balance realism with hope [32], [59] and [60], how this can be done is a dilemma not yet resolved [27] and [61].

Besides the content of information, the manner in which bad news is communicated is very important. Patients need an empathic doctor [3], [5], [62], [63], [64] and [65] but some studies indicate that during bad news consultations technical expertise is more important [18], [66] and [67]. It is important to know how oncologists can balance this need for both affective and task-oriented communication [68].

\subsection{Aim of the study}

So far, we do not know whether patients prefer more explicit or general information on the one hand and hopeful or realistic information on the other hand about the diagnosis and for which topics. The aim of this qualitative study is to explore how oncologists can balance these preferences when discussing the transition to palliative care.

\section{METHODS}

\subsection{Recruitment and sample characteristics}

For this qualitative study we focused on breast cancer because this disease affects almost only women and gender influences communication preferences [69]. We decided not to include incurable patients but female survivors and healthy women instead (age 18-65, with sufficient command of the Dutch language), because of ethical constraints. Similar approaches have been applied before, resulting in valid outcomes [17], [70] and [71]. Survivors were recruited through websites and in publications of the Dutch Breast Cancer Patient Advocacy Organization and a sister organization. Healthy women were recruited through selected healthrelated websites, message-boards at health service organizations and via snowball procedures.

\subsection{Ethical approval}

The study was approved by the Medical Ethics Committee of the University Medical Centre of Utrecht. 
Vliet, L. van, Francke, A., Tomson, S., Plum, N., Wall, E. van der, Bensing, J. When cure is no option: how explicit and hopeful can information be given? A qualitative study in breast cancer. Patient Education and Counseling: 2013, 90(3), 315-322

\subsection{Focus groups}

Ten focus groups (five with healthy women and five with survivors) of three to seven persons were set up. Prior to the focus group the participants' demographic characteristics were assessed. At the start of the focus group permission was asked to audiotape and videotape the discussion. The participants were asked to read a hypothetical case about a woman who hears from the oncologist that her recurrent breast cancer has spread and that she cannot be cured. They were asked to identify with this woman and then the discussion started, guided by the first author (LV) using a list with semi-structured questions (see Appendix A). The women were asked which topics they would wish to discuss in such a consultation, and whether they would prefer oncologists to be more explicit or general and more realistic or hopeful. Focus group sessions took about $3.5 \mathrm{~h}$.

\subsection{Analysis}

Data analysis started after the initial focus groups were held, and was part of a cyclical process of data collection - data analysis - data collection, etc. All focus group discussions were transcribed verbatim. Two researchers (LV and AF or ST) read all transcripts and independently wrote a memo for each interview in which they described the most important or remarkable outcomes. These memos were subsequently compared and discussed. Moreover, the first author (LV) and one co-author (ST) systematically coded the transcripts. Initial 'open coding' (initial codes given to fragments of text) was gradually replaced by 'axial coding' (describing codes and intergration in broader related concepts). In the last phase of 'selective coding' core concepts were determined and the relationships between concepts were interpreted [72] and [73]. Answers to the research questions were formulated by constant comparison between and within interview transcripts of the coded material. The coding, sorting and comparing of the interview fragments was facilitated by MAXQda software [74]. To improve the quality of the analyses, at different points interim analyses were discussed among the co-authors, who have a background in medicine, psychology, sociology or nursing. This 'peer debriefing' [75] prevents one-sided interpretations of the data. Since the last two focus group sessions provided no new themes related to the research questions, data saturation appears to have been reached as far as Caucasian Dutch women are concerned.

\section{RESULTS}

52 women participated in the study; 23 breast cancer survivors and 29 healthy women. Demographic variables are shown in Table 1.

\section{[TABLE 1]}

\subsection{From a lost future to a new future perspective}

The women agreed that hearing that their disease is incurable would destroy their future perspective in a split second. They thought that during the consultation, the oncologists' main task is to restore this perspective, by discussing different themes, resulting in the patients' feeling that they will be able to live full lives until the end.

I would want to leave with the feeling "I will go on with my life, despite the fact that I've had terrible news, and there's no cure, I'm going to try to make something of my life.” (healthy woman, age 59)

\subsubsection{Time to let the message sink in}

Before feeling able to engage in any discussion they would appreciate some time to let the news sink in. I would say 'Let two patients go ahead, because I first have to think about it (the diagnosis)'. (survivor, age 59)

After this pause they would want - more or less explicit - medical information and information about continued support.

\subsubsection{Honest medical information}

Above all, the women thought that oncologists should give honest medical information to make them understand their disease. They stressed that they only needed information personalized to their specific situation. Information would be needed concerning the characteristics of the disease (where the disease is 
Vliet, L. van, Francke, A., Tomson, S., Plum, N., Wall, E. van der, Bensing, J. When cure is no option: how explicit and hopeful can information be given? A qualitative study in breast cancer. Patient Education and Counseling: 2013, 90(3), 315-322

located, how it would develop, and predicted life expectancy). Additionally, information was required regarding available treatments.

I'd like to know, is it in my liver, bones or all over... Yes, just some kind of test results. (survivor, age 56) The first thing that crosses my mind is what the course of the disease will be like. What will it look like? (healthy woman, age 58)

\subsubsection{Level of preferred explicitness}

Although everyone stressed the importance of honest medical information, the women's preferred level of explicitness varied. All regarded it as fundamental to receive fairly explicit information concerning their medical diagnosis.

The medical situation now, that's a fact. They know exactly where it's located. So that's what I'd like to know, that's a starting point. (healthy woman, age 62)

However, focusing on prognosis, preferences varied widely. Some women explained that they would need very specific information, including statistics, to understand their situation. Others preferred general information (i.e. whether the oncologist expects them to live for some time) because when confronted with a time limit they would focus on that date. For examples see Box 1.

Box 1. Quotes from women preferring explicit or general prognostic information.

If a physician says: "Madam, in your situation, with your cancer cells and your metastases - and they can infer much from that - we know that..." It would be useless to hear that I will die between 1 and 10 years from now. That's not concrete enough, so they'd better say nothing then. If they say: "It's 3 years, give or take a year or two", yes. I do understand that they cannot say: "It will last 2 years and 4 months.” They cannot say that. But at least I have some kind of indication that they have taken a look at it. That would be specific enough, but not between 1 and 10 years. (survivor, age 55)

I would like to know very explicitly. Not too vague in terms like 'some years' or 'some months'. (healthy woman, age 59)

A kind of minimum-maximum perspective. Like, if it progresses very rapidly and invasively, how long do I have then? And if I'm lucky, how long might I have? If it's 3 weeks or 3 years, well, give me some idea. (survivor, age 60)

They don't know what will happen. So, they cannot say, because they don't know. They can give a general indication: "Often when the disease has progressed like this so far, then it will be approximately so many years"; but more than that they cannot say. (healthy woman, age 26)

Perhaps some estimate. There will be degrees varying from 'this will be over next week' to 'it will take months or years'. (healthy woman, age 23)

This variation applied to a lesser extent to information regarding palliative treatments. It would be sufficient for many to hear that there are still options. During follow-up consultations they would gradually need more explicit information concerning the treatments and their side effects to make well-informed decisions. This would be too much to comprehend during the first consultation.

I would appreciate it if they would tell me: "There are several options available for treatment which we can consider. And I think it would be wise to talk about that during another appointment.” (survivor, age 56)

\subsubsection{Availability of continued support}

Besides medical information, the interviewees found it important to discuss the availability of continued support. Women wanted to know how they are guided by health care professionals during their disease. Most often, participants mentioned the need for specific telephone numbers to contact the hospital directly if necessary. They envisaged a central role for a specialist breast cancer nurse who would function as a contact person. Emotional guidance could be offered both for patients and their families. Even women who indicated not to need such guidance would appreciate the gesture. Interestingly, there was a preference for early discussion of the support available during later stages of the disease.

And the specialist nurse, basically, provides more support, because nurses see much more of a patient in the hospital department. (survivor, age 63)

I would really appreciate if a physician would say: "Well, if you have any questions or you are scared or whatever, you can always call.” (healthy woman, age 50) 
Vliet, L. van, Francke, A., Tomson, S., Plum, N., Wall, E. van der, Bensing, J. When cure is no option: how explicit and hopeful can information be given? A qualitative study in breast cancer. Patient Education and Counseling: 2013, 90(3), 315-322

\subsubsection{Hope has many faces: there's always something that can be done}

When introducing the topic of 'hope', a few women associated 'hope' purely with cure and preferred terms such as 'positive information'. Irrespective of how it was labeled, all participants found it extremely important for patients never to feel that 'nothing can be done'.

Because if the physician were to say: "Well madam, there is no hope left", then someone might as well punch you in the face, because that's what just happened. (healthy woman, age 58)

The feeling that something is being done, ranging from treatments aimed at prolonging life to pain medication to improve quality of life, was perceived as hopeful. Oncologists could focus on the possibilities to extend life through treatments and on good quality of life.

For me it's just the fact that something is being done, that gives hope. It doesn't have to be put like: “This can save your life", but the person feels that there are things that can be done. (healthy woman, age 26)

Women often said that they would be scared 'to be left alone'. They wanted an oncologist to reassure them that they will be taken care of and not be abandoned throughout the disease.

Before you leave, they might say: "We will take good care of you, we'll make sure that you don't have pain, that you will die peacefully and we'll be standing by you to the very end.” (survivor, age 50)

Last, hope was also something that comes from within, such as hope for a miracle. According to the participants, oncologists ought not to feed this hope but they can tell patients they would be pleased if they beat the odds.

\subsubsection{Space to choose}

A last element that would be important for women - and defined as hopeful - was knowing that they can make their own decisions in the future. Reassurance of non-abandonment was a prerequisite for this; women could only feel able to make own decisions when they were sure that they would be taken care of unconditionally. Some wanted to make decisions on their own while others preferred to follow an oncologist's expertise and decide together.

Hopeful doesn't mean to me 'live longer'. It's more the confidence that I can manage my own life: "We won’t abandon you. We will be standing by you.” (survivor, age 58)

\subsubsection{Graphic representation}

The potential relationships among the described themes are displayed in Fig. 1. This figure illustrates a patient perspective on discussing the transition to palliative care by providing information on various topics and balancing explicit with general and hopeful with realistic information, in order to create a new future perspective.

\section{[FIGURE 1]}

\subsection{Differences in information preferences}

As the presented figure was based on participants' views, there were variations in how the agreed needs were preferred to be discussed.

\subsubsection{Differences associated with participant characteristics}

Women who expressed a greater need to be in control and make their own decisions preferred more explicit information. Also, experiences women had with cancer influenced preferences; good and bad experiences of loved ones were often given as reasons for preferences. This was most apparent for not wanting to hear an explicit time-frame when loved ones had outlived poor prognoses.

Too often I've seen people get a bad prognosis and then they are still alive after 5 or 10 years. So that's why I wouldn't want to know. (healthy woman, age 61)

Additionally, the women recognized that preferences vary and they put forward variables that may influence these: older generations may prefer general information - which they based on examples of their own parents - and non-western immigrants may have other needs as well.

I presume that if it were a typical non-western woman, a completely different approach will be needed. Discussing the disease is 'not done' in their culture. (healthy woman, age 58) 
Vliet, L. van, Francke, A., Tomson, S., Plum, N., Wall, E. van der, Bensing, J. When cure is no option: how explicit and hopeful can information be given? A qualitative study in breast cancer. Patient Education and Counseling: 2013, 90(3), 315-322

\subsubsection{Handling differences}

The interviewees thought that oncologists need to tailor their communication. They suggested that oncologists go by their intuition and sense what kind of woman they are talking to. However, this may require too much interpersonal sensitivity for some oncologists. An alternative suggestion was to ask the patients how explicit the information should be; possibly right at the start of the consultation. Preferably, oncologists should provide general information per topic and ask whether this is enough.

If someone asks: "What about the pain?", then you explain about pain medication and you ask: "Is this enough information for the moment?” So you adjust your information. (healthy woman, age 53)

\subsubsection{Differences between survivors and healthy women}

Overall, there appeared to be little difference in survivors' and healthy women's perceptions, with two exceptions. First, survivors more often expressed a strong desire to manage their own life and, consequently, they preferred more explicit information.

I don’t want him to tell me: “Go take these pills.” (...) No, I want to participate in decisions. I want to hear all the 'ins and outs'. (survivor, age 63)

Second, survivors sometimes expressed - contrary to healthy women - that they had low expectations of oncologists' communication skills.

But my expectations are so low. He will only think: "Do you need a referral for a psychologist?" (survivor, age 49)

\subsection{Preferences for communication}

Last, women brought up two overarching expectations regarding oncologists’ communication.

\subsubsection{Getting a feeling of sufficient time}

Participants agreed that oncologists have to create the impression of sufficient time (e.g. by avoiding interruptions). They also expected oncologists to be well prepared and to advise patients to bring a companion when test results are discussed.

He has to give me the feeling that he's there for me and has all the time in the world. Even if he hasn't, just create that feeling. (survivor, age 42)

\subsubsection{Empathy with a professional distance}

Women expected oncologists to show empathy (e.g. by maintaining eye contact) and they wanted to be taken seriously and listened to. Simultaneously, they expected oncologists to keep a professional distance; oncologists cannot become too emotionally involved.

When someone cries with you, that doesn't help. But he can make it feel like 'how do you feel now'. (survivor, age 57)

\section{DISCUSSION AND CONCLUSION}

\subsection{Discussion}

This study focused on how - from a perspective of survivors and healthy women - oncologists can balance explicit with general and hopeful with realistic information when discussing the transition to palliative care in breast cancer. Women thought that oncologists ought to help patients regain a sense of future perspective, which can be achieved by providing relevant, realistic medical information - while tailoring the level of explicitness - and information about support. The needed hope has many faces and can be given by stressing (treatment) possibilities and non-abandonment while respecting patients' choices. Meanwhile, oncologists have to take into account variations in preferences.

We found, in line with recent reviews, that information about the disease's characteristics, prognosis and treatment options is needed during this consultation [28], [33] and [76] as well as information regarding the hospital's support throughout the illness. Some guidelines have suggested introducing palliative care services - covering continued support - early [16], [24] and [77]. Patients indeed appreciate regular consultations [48] and [63] or direct contact numbers [48]. However, until now, continued guidance has not received a prominent role in the literature on breaking bad news. 
While it has been suggested to negotiate the timing of discussing these topics [78], our study found that oncologists may have to focus on the explicitness of medical information instead. Most women preferred information regarding the disease and treatment options (immediately or later) to be discussed explicitly. Previous studies showed that patients indeed require much information on these topics [23], [42], [76] and [79]. The crux seems to be the level of explicitness in prognostic information, as both the interviewed women's and clinical patients' preferences [21], [30], [35], [39], [42], [46] and [80] vary widely. Marwit and Datson [81] suggested that the distinction often made between full versus non-disclosure is not sensitive enough as many patients need partial and paced disclosure.

Our analysis indicated that factors predicting these preferences may include the need for control and previous experiences with cancer. Interestingly, one study found that positive experiences with death increased cancer patients' preferences for detailed prognostic information [81]. These experiences could be important for oncologists to explore when discussing life expectancy.

Although the tailoring of information seems important, oncologists tend to give information routinely [82]. Tailoring information implies that oncologists adapt to patients’ preferences [64]. Physicians sometimes rely on their intuition when providing information but their predictions are often incorrect [83], [84] and [85]. Alternatively, oncologists can ask patients about their preferences [24], [86] and [87], which is often overlooked [88]. These two approaches were also suggested in the current study. One interesting study found that patients' initial response was to say they wished to receive all information, while in further questioning some preferred general prognostic information instead [89]. So, it may be better to start by giving general information per topic and then ask whether patients prefer more explicit information, as suggested by our results.

Our analysis indicated that providing personally relevant information is another important aspect of tailoring, which highlights a discrepancy in clinical practice. While oncologists are inclined to give primarily technical information ('type of treatment') patients need to know how this information applies to them instead ('will I get chemo and go bald?') [90]. As patients are known to recall little (technical [44]) information when receiving bad news [91] and [92], the need for relevant information becomes even more apparent.

Regarding hope versus realism, our study found that this may not be such a contradiction as suggested in the literature [37], [60] and [93]. Still, the first association with hope was cure, which is unrealistic in this situation and should thus not be given by oncologists. That incurable patients still hope for a miracle [37] and [39] may stem from other sources [94]. Our results seem to indicate that oncologists fundamentally ought to provide realistic information, meanwhile generating (realistic) hope by different means. The quotation that best reflects this is: "There is always something that can be done" which covers hopeful information regarding (treatment) options, some time left and non-abandonment. While (treatment) options have previously been labeled as hope [37], [53] and [67], also the hope for longer survival is important to patients [54] and [55]. Knowing that one will not be abandoned by the hospital becomes more important for patients during disease progression as a source of hope [95] and [96]. Last, the interviewees needed to know that they can make their own decisions - on the premise of being taken care of unconditionally. Although this element of hope has sometimes been mentioned by patients [37], [48] and [97] and guidelines [16] and [77], it has not received much attention in studies on breaking bad news.

Besides providing information, one of the core elements of communication is 'fostering the relationship' [98]. Oncologists who are both empathically and medically competent during bad news conversations are the most valued [99] and [100], indicating that clinical patients rate both qualities highly. This was also found in the present study. Nevertheless, in a recent study only $62 \%$ of cancer patients thought their diagnosis was conveyed in an empathic manner [65]. Additionally, survivors in our study had lower expectations of oncologists' communication than healthy women.

\subsubsection{Limitations}

As qualitative research requires detailed data collection, sample sizes are often small and might therefore not be representative of the total population. We failed to include women of ethnic minorities, whose perspectives on good communication might differ [101]. Participants were educated and stated that they were assertive, which may be attributable to recruitment through the Patient Advocacy Organisation and advertisements. Therefore, quantitative studies should be conducted to assess the generalizability of the findings. 
Vliet, L. van, Francke, A., Tomson, S., Plum, N., Wall, E. van der, Bensing, J. When cure is no option: how explicit and hopeful can information be given? A qualitative study in breast cancer. Patient Education and Counseling: 2013, 90(3), 315-322

Using proxies for incurable cancer patients rather than incurable patients themselves is a limitation of this study. In clinical care patients may be emotionally overwhelmed after hearing this diagnosis [36] and [102] and react less rationally than the interviewed women. Yet, the current approach has been applied in previous studies in which lay people [64], curable patients [81] and relatives [34], [37], [101], [103] and [104] reflected on communication in palliative care. Almost all the healthy women in our study had secondhand experience of this type of consultation. Finally, both the survivors' and the healthy women's perceptions largely overlapped, providing additional evidence for the validity of this methodology.

\subsubsection{Future research}

Future research could try to disentangle the effect of explicit versus general information on various participants. Additionally, the various forms of hopeful information could be further studied, especially reassurance for non-abandonment. Last, the potential relationships among the themes could be investigated. Such studies could test and clarify the potential application of the results of this explorative study in clinical practice.

\subsection{Conclusion}

Women who imagined themselves to be in the situation of hearing life-limiting information thought they would need realistic medical information and information regarding support. The maintenance of hope was not restricted to the (treatment) possibilities left, but was particularly based on the reassurance to always be taken care of and the confidence to remain able to make one's own decisions.

\subsection{Practice implications}

Oncologists should be aware that providing life-limiting information could shatter a patient's future perspective. The results presented provide oncologists with suggestions from a patient viewpoint to create a new future perspective, while tailoring explicitness of information and providing realistic hope. These results may have relevance for other health professionals, particularly oncology nurses.

\section{ROLE OF FUNDING}

This project was funded by the Spinoza Prize awarded to Prof. Jozien Bensing, PhD by the Dutch Research Council (NWO). The NWO was not involved in the research process.

\section{CONFLICT OF INTEREST}

The authors have no conflicts of interest to declare.

\section{ACKNOWLEDGEMENTS}

We would like to thank all the women who participated in the focus groups and the Dutch Breast Cancer Patient Advocacy Organization and its sister organization, Amazones, for their help in facilitating the recruitment. We would like to thank Akke Albada for comments on an earlier manuscript.

\section{REFERENCES}

[1] D. Roter and J.A. Hall, Doctors talking with patients/patients talking with doctors: improving communication in medical visits, Praeger, Westport, CT (2006).

[2] A. Lienard, I. Merckaert, Y. Libert, N. Delvaux, S. Marchal and J. Boniver et al., Factors that influence cancer patients' and relatives' anxiety following a three-person medical consultation: impact of a communication skills training program for physicians, Psychooncology 17 (2008), pp. 488-496.

[3] P.E. Schofield, P.N. Butow, J.F. Thompson, M.H. Tattersall, L.J. Beeney and S.M. Dunn, Psychological responses of patients receiving a diagnosis of cancer, Ann Oncol 14 (2003), pp. 48-56.

[4] P.R. Helft and S. Petronio, Communication pitfalls with cancer patients: "hit-and-run" deliveries of bad news, J Am Coll Surg 205 (2007), pp. 807-811.

[5] L. Fallowfield and V. Jenkins, Communicating sad, bad, and difficult news in medicine, Lancet 363 (2004), pp. 312-319.

[6] M. Friedrichsen and A. Milberg, Concerns about losing control when breaking bad news to terminally ill patients with cancer: physicians' perspective, J Palliat Med 9 (2006), pp. 673-682. 
Vliet, L. van, Francke, A., Tomson, S., Plum, N., Wall, E. van der, Bensing, J. When cure is no option: how explicit and hopeful can information be given? A qualitative study in breast cancer. Patient Education and Counseling: 2013, 90(3), 315-322

[7] M.W. Rabow and S.J. McPhee, Beyond breaking bad news: how to help patients who suffer, West J Med 171 (1999), pp. 260-263.

[8] A. Girgis, R.W. Sanson-Fisher and M.J. Schofield, Is there consensus between breast cancer patients and providers on guidelines for breaking bad news?, Behav Med 25 (1999), pp. 69-77.

[9] G.K. VandeKieft, Breaking bad news, Am Fam Physician 64 (2001), pp. 1975-1978.

[10] P. Maguire and C. Pitceathly, Key communication skills and how to acquire them, Brit Med J 325 (2002), pp. 697-700.

[11] C.L. Paul, T. Clinton-McHarg, R.W. Sanson-Fisher, H. Douglas and G. Webb, Are we there yet? The state of the evidence base for guidelines on breaking bad news to cancer patients, Eur J Cancer 45 (2009), pp. 2960-2966.

[12] S. Eggly, L.A. Penner, M. Greene, F.W. Harper, J.C. Ruckdeschel and T.L. Albrecht, Information seeking during "bad news" oncology interactions: question asking by patients and their companions, Soc Sci Med 63 (2006), pp. 2974-2985.

[13] National Health and Medical Research Council, Clinical practice guidelines for the management of advanced breast cancer UK (2001).

[14] Institute for Clinical Systems Improvement (ICSI), Palliative care USA (2009).

[15] Vereniging Integrale Kankercentra. Slecht nieuws gesprek. Regionale richtlijn IKL, Versie: 1.02003.

[Organisation Integrated Cancer Centers. Bad news conversation. Regional guideline IKL, Verson 1.0 The Netherlands 2003].

[16] A. Girgis and R.W. Sanson-Fisher, Breaking bad news: consensus guidelines for medical practitioners, J Clin Oncol 13 (1995), pp. 2449-2456.

[17] S.M. Dowsett, J.L. Saul, P.N. Butow, S.M. Dunn, M.J. Boyer and R. Findlow et al., Communication styles in the cancer consultation: preferences for a patient-centred approach, Psychooncology 9 (2000), pp. 147-156.

[18] P.A. Parker, W.F. Baile, C. de Moor, R. Lenzi, A.P. Kudelka and L. Cohen, Breaking bad news about cancer: patients' preferences for communication, J Clin Oncol 19 (2001), pp. 2049-2056.

[19] T.B. Brewin, Three ways of giving bad news, Lancet 337 (1991), pp. 1207-1209.

[20] P.M. Ellis and M.H. Tattersall, How should doctors communicate the diagnosis of cancer to patients?, Ann Med 31 (1999), pp. 336-341.

[21] R.G. Hagerty, P.N. Butow, P.A. Ellis, E.A. Lobb, S. Pendlebury and N. Leighl et al., Cancer patient preferences for communication of prognosis in the metastatic setting, J Clin Oncol 22 (2004), pp. 17211730.

[22] S.M. Parker, J.M. Clayton, K. Hancock, S. Walder, P.N. Butow and S. Carrick et al., A systematic review of prognostic/end-of-life communication with adults in the advanced stages of a life-limiting illness: patient/caregiver preferences for the content, style, and timing of information, J Pain Symptom Manage 34 (2007), pp. 81-93.

[23] V. Jenkins, L. Fallowfield and J. Saul, Information needs of patients with cancer: results from a large study in UK cancer centres, Br J Cancer 84 (2001), pp. 48-51.

[24] P. Schofield, M. Carey, A. Love, C. Nehill and S. Wein, 'Would you like to talk about your future treatment options'? Discussing the transition from curative cancer treatment to palliative care, Palliat Med 20 (2006), pp. 397-406.

[25] L.J. Fallowfield, V.A. Jenkins and H.A. Beveridge, Truth may hurt but deceit hurts more: communication in palliative care, Palliat Med 16 (2002), pp. 297-303.

[26] B. Aabom, J. Kragstrup, H. Vondeling, L.S. Bakketeig and H. Stovring, Defining cancer patients as being in the terminal phase: who receives a formal diagnosis, and what are the effects?, J Clin Oncol 23 (2005), pp. 7411-7416.

[27] S. Innes and S. Payne, Advanced cancer patients' prognostic information preferences: a review, Palliat Med 23 (2009), pp. 29-39.

[28] M. Fujimori and Y. Uchitomi, Preferences of cancer patients regarding communication of bad news: a systematic literature review, Jpn J Clin Oncol 39 (2009), pp. 201-216.

[29] J. Ohlen, L.C. Elofsson, L.C. Hyden and F. Friberg, Exploration of communicative patterns of consultations in palliative cancer care, Eur J Oncol Nurs 12 (2008), pp. 44-52.

[30] R.G. Hagerty, P.N. Butow, P.M. Ellis, E.A. Lobb, S.C. Pendlebury and N. Leighl et al., Communicating with realism and hope: incurable cancer patients' views on the disclosure of prognosis, J Clin Oncol 23 (2005), pp. 1278-1288.

[31] R.G. Hagerty, P.N. Butow, P.M. Ellis, S. Dimitry and M.H. Tattersall, Communicating prognosis in cancer care: a systematic review of the literature, Ann Oncol 16 (2005), pp. 1005-1053. 
Vliet, L. van, Francke, A., Tomson, S., Plum, N., Wall, E. van der, Bensing, J. When cure is no option: how explicit and hopeful can information be given? A qualitative study in breast cancer. Patient Education and Counseling: 2013, 90(3), 315-322

[32] P.A. Parker, J. Aaron and W.F. Baile, Breast cancer: unique communication challenges and strategies to address them, Breast J 15 (2009), pp. 69-75.

[33] A.L. Back, W.G. Anderson, L. Bunch, L.A. Marr, J.A. Wallace and H.B. Yang et al., Communication about cancer near the end of life, Cancer 113 (2008), pp. 1897-1910.

[34] J.M. Clayton, P.N. Butow, R.M. Arnold and M.H. Tattersall, Discussing life expectancy with terminally ill cancer patients and their carers: a qualitative study, Support Care Cancer 13 (2005), pp. 733-742.

[35] M.M. Barnett, Does it hurt to know the worst? - psychological, information preferences and understanding of prognosis in patients with advanced cancer, Psycho-Oncology 15 (2006), pp. 44-55.

[36] G. Rodin, J.A. Mackay, C. Zimmermann, C. Mayer, D. Howell and M. Katz et al., Clinician-patient communication: a systematic review, Support Care Cancer 17 (2009), pp. 627-644.

[37] J.M. Clayton, P.N. Butow, R.M. Arnold and M.H. Tattersall, Fostering coping and nurturing hope when discussing the future with terminally ill cancer patients and their caregivers, Cancer 103 (2005), pp. 19651975.

[38] J.M. Clayton, P.N. Butow and M.H. Tattersall, When and how to initiate discussion about prognosis and end-of-life issues with terminally ill patients, J Pain Symptom Manage 30 (2005), pp. 132-144.

[39] P. Kirk, I. Kirk and L.J. Kristjanson, What do patients receiving palliative care for cancer and their families want to be told? A Canadian and Australian qualitative study, Brit Med J (2004), pp. $1343-1349$.

[40] P.N. Butow, S. Dowsett, R. Hagerty and M.H. Tattersall, Communicating prognosis to patients with metastatic disease: what do they really want to know?, Support Care Cancer 10 (2002), pp. 161-168.

[41] J. Benson and N. Britten, Respecting the autonomy of cancer patients when talking with their families: qualitative analysis of semistructured interviews with patients, Brit Med J 313 (1996), pp. 729-731.

[42] G.M. Leydon, M. Boulton, C. Moynihan, A. Jones, J. Mossman and M. Boudioni et al., Faith, hope, and charity: an in-depth interview study of cancer patients' information needs and information-seeking behavior, West J Med 173 (2000), pp. 26-31.

[43] E.B. Elkin, S.H. Kim, E.S. Casper, D.W. Kissane and D. Schrag, Desire for information and involvement in treatment decisions: elderly cancer patients' preferences and their physicians' perceptions, J Clin Oncol 25 (2007), pp. 5275-5280.

[44] J. Jansen, J. van Weert, N. van der Meulen, S. van Dulmen, T. Heeren and J. Bensing, Recall in older cancer patients: measuring memory for medical information, Gerontologist 48 (2008), pp. 149-157.

[45] S.A. Kaplowitz, S. Campo and W.T. Chiu, Cancer patients' desires for communication of prognosis information, Health Commun 14 (2002), pp. 221-241.

[46] T.R. Fried, E.H. Bradley and J. O'Leary, Prognosis communication in serious illness: perceptions of older patients, caregivers, and clinicians, J Am Geriatr Soc 51 (2003), pp. 1398-1403.

[47] J.S. Kutner, J.F. Steiner, K.K. Corbett, D.W. Jahnigen and P.L. Barton, Information needs in terminal illness, Soc Sci Med 48 (1999), pp. 1341-1352.

[48] T.C. Randall and A.M. Wearn, Receiving bad news: patients with haematological cancer reflect upon their experience, Palliat Med 19 (2005), pp. 594-601.

[49] K. Hancock, J.M. Clayton, S.M. Parker, S. Wal der, P.N. Butow and S. Carrick et al., Truth-telling in discussing prognosis in advanced life-limiting illnesses: a systematic review, Palliat Med 21 (2007), pp. 507-517.

[50] J.M. Clayton, K. Hancock, S. Parker, P.N. Butow, S. Walder and S. Carrick et al., Sustaining hope when communicating with terminally ill patients and their families: a systematic review, Psychooncology 17 (2008), pp. 641-659.

[51] R.T. Penson, F. Gu, S. Harris, M.M. Thiel, N. Lawton and A.F. Fuller Jr. et al., Hope, Oncologist 12 (2007), pp. 1105-1113.

[52] T.M. Robinson, S.C. Alexander, M. Hays, A.S. Jeffreys, M.K. Olsen and K.L. Rodriguez et al., Patientoncologist communication in advanced cancer: predictors of patient perception of prognosis, Supportive Care in Cancer 16 (2008), pp. 1049-1057.

[53] S.N. Whitney, L.B. McCullough, E. Fruge, A.L. McGuire and R.J. Volk, Beyond breaking bad news: the roles of hope and hopefulness, Cancer 113 (2008), pp. 442-445.

[54] E. Benzein, A. Norberg and B.I. Saveman, The meaning of the lived experience of hope in patients with cancer in palliative home care, Palliat Med 15 (2001), pp. 117-126.

[55] N.A. Pattison and C. Lee, Hope Against Hope in Cancer at the End of Life, J Relig Health (2009).

[56] T.J. Smith, L.A. Dow, E. Virago, J. Khatcheressian, L.J. Lyckholm and R. Matsuyama, Giving honest information to patients with advanced cancer maintains hope, Oncology 24 (2010), pp. 521-525.

[57] P.A. Berry, The withholding of truth when counselling relatives of the critically ill: a rational defence, Clin Ethics 3 (2008), pp. 42-45. 
Vliet, L. van, Francke, A., Tomson, S., Plum, N., Wall, E. van der, Bensing, J. When cure is no option: how explicit and hopeful can information be given? A qualitative study in breast cancer. Patient Education and Counseling: 2013, 90(3), 315-322

[58] G. Johnston and C. Abraham, Managing awareness: negotiating and coping with a terminal prognosis, Int J Palliat Nurs 6 (2000), pp. 485-494.

[59] P.A. Francis, Surprised by hope, J Clin Oncol 26 (2008), pp. 6001-6002.

[60] B.E. Kiely, M.H. Tattersall and M.R. Stockler, Certain death in uncertain time: informing hope by quantifying a best case scenario, J Clin Oncol 28 (2010), pp. 2802-2804.

[61] C.G. Shields, C.J. Coker, S.S. Poulsen, J.M. Doyle, K. Fiscella and R.M. Epstein et al., Patientcentered communication and prognosis discussions with cancer patients, Patient Educ Couns 77 (2009), pp. 437-442.

[62] J.T. Ptacek and J.J. Ptacek, Patients' perceptions of receiving bad news about cancer, J Clin Oncol 19 (2001), pp. 4160-4164.

[63] P. Salander, Bad news from the patient's perspective: an analysis of the written narratives of newly diagnosed cancer patients, Soc Sci Med 55 (2002), pp. 721-732.

[64] M. Quirk, K. Mazor, H.L. Haley, M. Philbin, M. Fischer and K. Sullivan et al., How patients perceive a doctor's caring attitude, Patient Educ Couns 72 (2008), pp. 359-366.

[65] W. Spiegel, T. Zidek, M. Maier, C. Vutuc, K. Isak and H. Karlic et al., Breaking bad news to cancer patients: survey and analysis, Psychooncology 18 (2009), pp. 179-186.

[66] J.H. Wiggers, K.O. Donovan, S. Redman and R.W. Sanson-Fisher, Cancer patient satisfaction with care, Cancer 66 (1990), pp. 610-616.

[67] A.N. Sardell and S.J. Trierweiler, Disclosing the cancer diagnosis. Procedures that influence patient hopefulness, Cancer 72 (1993), pp. 3355-3365.

[68] J. Bensing, Doctor-patient communication and the quality of care, Soc Sci Med 32 (1991), pp. 13011310.

[69] H. Wessels, A. de Graeff, K. Wynia, M. de Heus, C.L. Kruitwagen and G.T. Woltjer et al., Genderrelated needs and preferences in cancer care indicate the need for an individualized approach to cancer patients, Oncologist 15 (2010), pp. 648-655.

[70] L.A. Fogarty, B.A. Curbow, J.R. Wingard, K. McDonnell and M.R. Somerfield, Can 40 seconds of compassion reduce patient anxiety?, J Clin Oncol 17 (1999), pp. 371-379.

[71] M. Schmid Mast, A. Kindlimann and W. Langewitz, Recipients' perspective on breaking bad news: how you put it really makes a difference, Patient Educ Couns 58 (2005), pp. 244-251.

[72] K. Charmaz, Constructing grounded theory. A practical guide through qualitative analysis, Sage Publications, London (2006).

[73] $\mathrm{H}$. Boeije, A purposeful approach to the constant comparative method in the analysis of qualitative interviews, Qual Quant 36 (2002), pp. 391-409.

[74] Maxqda2: Software for Qualitative Data Analysis [computer program]. Berlin: VERBI software: Consult Sozialforschung, 2004.

[75] A. Strauss and J. Corbin, Basics of qualitative research. Grounded theory procedures and techniques, Sage Publications, Newbury Park, CA (1990).

[76] C.M. Gaston and G. Mitchell, Information giving and decision-making in patients with advanced cancer: a systematic review, Soc Sci Med 61 (2005), pp. 2252-2264.

[77] W.F. Baile, R. Buckman, R. Lenzi, G. Glober, E.A. Beale and A.P. Kudelka, SPIKES-A six-step protocol for delivering bad news: application to the patient with cancer, Oncologist 5 (2000), pp. 302-311.

[78] S.M. Lagarde, S.J. Franssen, J.R. van Werven, E.M. Smets, T.C. Tran and H.W. Tilanus et al., Patient preferences for the disclosure of prognosis after esophagectomy for cancer with curative intent, Ann Surg Oncol 15 (2008), pp. 3289-3298.

[79] L.J. Fallowfield, Treatment decision-making in breast cancer: the patient-doctor relationship, Breast Cancer Res Treat 112 (Suppl. 1) (2008), pp. 5-13.

[80] L. Fallowfield, V. Jenkins, V. Farewell, J. Saul, A. Duffy and R. Eves, Efficacy of a Cancer Research UK communication skills training model for oncologists: a randomised controlled trial, The Lancet 359 (2002), pp. 650-656.

[81] S.J. Marwit and S.L. Datson, Disclosure preferences about terminal illness: an examination of decisionrelated factors, Death Stud 26 (2002), pp. 1-20.

[82] S.M. Dunn, P.N. Butow, M.H. Tattersall, Q.J. Jones, J.S. Sheldon and J.J. Taylor et al., General information tapes inhibit recall of the cancer consultation, J Clin Oncol 11 (1993), pp. 2279-2285.

[83] S. Ford, L. Fallowfield and S. Lewis, Can oncologists detect distress in their out-patients and how satisfied are they with their performance during bad news consultations?, Br J Cancer 70 (1994), pp. 767770. 
Vliet, L. van, Francke, A., Tomson, S., Plum, N., Wall, E. van der, Bensing, J. When cure is no option: how explicit and hopeful can information be given? A qualitative study in breast cancer. Patient Education and Counseling: 2013, 90(3), 315-322

[84] C.F. Quirt, W.J. Mackillop, A.D. Ginsburg, L. Sheldon, M. Brundage and P. Dixon et al., Do doctors know when their patients don't? A survey of doctor-patient communication in lung cancer, Lung Cancer 18 (1997), pp. 1-20.

[85] E. Bruera, J.S. Willey, J.L. Palmer and M. Rosales, Treatment decisions for breast carcinoma: patient preferences and physician perceptions, Cancer 94 (2002), pp. 2076-2080.

[86] A.L. Back and R.M. Arnold, Discussing prognosis: "how much do you want to know?" talking to patients who do not want information or who are ambivalent, J Clin Oncol 24 (2006), pp. 4214-4217.

[87] J.E. Groopman, A strategy for hope: a commentary on necessary collusion, J Clin Oncol 23 (2005), pp. 3151-3152.

[88] N. Leighl, M. Gattellari, P. Butow, R. Brown and M.H. Tattersall, Discussing adjuvant cancer therapy, J Clin Oncol 19 (2001), pp. 1768-1778.

[89] J.R. Curtis, R. Engelberg, J.P. Young, L.K. Vig, L.F. Reinke and M.D. Wenrich et al., An approach to understanding the interaction of hope and desire for explicit prognostic information among individuals with severe chronic obstructive pulmonary disease or advanced cancer, J Palliat Med 11 (2008), pp. 610-620.

[90] S. Chaitchik, S. Kreitler, S. Shaked, I. Schwartz and R. Rosin, Doctor-patient communication in a cancer ward, J Cancer Educ 7 (1992), pp. 41-54.

[91] R.F. Brown, P.N. Butow, S.M. Dunn and M.H. Tattersall, Promoting patient participation and shortening cancer consultations: a randomised trial, Br J Cancer 85 (2001), pp. 1273-1279.

[92] J. Jansen, P.N. Butow, J.C. van Weert, S. van Dulmen, R.J. Devine and T.J. Heeren et al., Does age really matter? Recall of information presented to newly referred patients with cancer, J Clin Oncol 26 (2008), pp. 5450-5457.

[93] M.D. Wenrich, J.R. Curtis, S.E. Shannon, J.D. Carline, D.M. Ambrozy and P.G. Ramsey, Communicating with dying patients within the spectrum of medical care from terminal diagnosis to death, Arch Intern Med 161 (2001), pp. 868-874.

[94] M.L. Slevin, S.E. Nichols, S.M. Downer, P. Wilson, T.A. Lister and S. Arnott et al., Emotional support for cancer patients: what do patients really want?, Br J Cancer 74 (1996), pp. 1275-1279.

[95] I.R. Byock, The nature of suffering and the nature of opportunity at the end of life, Clin Geriatr Med 12 (1996), pp. 237-252.

[96] T.E. Quill and C.K. Cassel, Nonabandonment: a central obligation for physicians, Ann Intern Med 122 (1995), pp. 368-374.

[97] P.N. Butow, M. Maclean, S.M. Dunn, M.H. Tattersall and M.J. Boyer, The dynamics of change: cancer patients' preferences for information, involvement and support, Ann Oncol 8 (1997), pp. 857-863.

[98] $\mathrm{H}$. de Haes and J. Bensing, Endpoints in medical communication research, proposing a framework of functions and outcomes, Patient Educ Couns 74 (2009), pp. 287-294.

[99] M.J. Friedrichsen, P.M. Strang and M.E. Carlsson, Breaking bad news in the transition from curative to palliative cancer care-patient's view of the doctor giving the information, Support Care Cancer 8 (2000), pp. 472-478.

[100] J.C. van Weert, J. Jansen, G.J. de Bruijn, J. Noordman, S. van Dulmen and J.M. Bensing, QUOTEchemo: a patient-centred instrument to measure quality of communication preceding chemotherapy treatment through the patient's eyes, Eur J Cancer 45 (2009), pp. 2967-2976.

[101] F.M. de Graaff, A.L. Francke, M.E. van den Muijsenbergh and S. van der Geest, 'Palliative care': a contradiction in terms? A qualitative study of cancer patients with a Turkish or Moroccan background, their relatives and care providers, BMC Palliat Care 9 (2010), pp. 19-32.

[102] R.M. Epstein and R.L. Street, Patient-centered communication in cancer care: promoting healing and reducing suffering, National Cancer Institute (2007).

[103] J.M. Clayton, P.N. Butow, R.M. Arnold and M.H. Tattersall, Discussing end-of-life issues with terminally ill cancer patients and their carers: a qualitative study, Support Care Cancer 13 (2005), pp. 589-599.

[104] A.L. Francke and D.L. Willems, Terminal patients' awareness of impending death: the impact upon requesting adequate care, Cancer Nurs 28 (2005), pp. 241-247.

\section{TABLES APPENDIXES FIGURES BOXES}


Vliet, L. van, Francke, A., Tomson, S., Plum, N., Wall, E. van der, Bensing, J. When cure is no option: how explicit and hopeful can information be given? A qualitative study in breast cancer. Patient Education and Counseling: 2013, 90(3), 315-322

\section{APPENDIX A. CASE USED IN FOCUS GROUPS}

Try to imagine yourself in the following position. You are a 45-year-old female, married and a mother of two children. Four years ago, you discovered a lump in your left breast. This turned out to be malignant. Fortunately, the tumor was small, $1.5 \mathrm{~cm}$, and was found to be confined to the breast. You were treated with surgery, radiotherapy and adjuvant chemotherapy. One month ago you again felt a small lump in your left breast. Physical examination by the surgeon revealed several lymph nodes in the axilla, suggestive for pathological involvement, i.c. the lymph nodes containing cancer cells. You underwent a bone scan and CT scan of the lungs and liver. These investigations revealed metastases in your bones and liver. There are no treatments available that will cure you. The doctor wants to discuss your future expectations.

Question 1:

Which topics do you think are most important to discuss when a doctor raises the issue of future expectations with a breast cancer patient who is incurable?

Question 2:

About which of these topics would you prefer to receive explicit information and about which topics would you prefer to receive more general information?

Question 3:

Can you give concrete examples of how an oncologist might give specific or general information?

Question 4:

About which of these topics would you prefer realistic information and about which topics would you prefer more hopeful information?

Question 5:

Can you give concrete examples about how an oncologist might give realistic or hopeful information? Question 6:

We are also interested in your opinion about the manner in which a doctor gives you information; how do you think that a doctor should behave in this situation?

Question 7:

Do you have any other important opinions or remarks about anything that has been discussed today that you would like to share?

\section{Table 1}

Demographic variables of focus group participants.

\begin{tabular}{lll}
\hline Variable & $\begin{array}{l}\text { Breast cancer } \\
\text { survivors }(n=23)\end{array}$ & $\begin{array}{l}\text { Healthy } \\
\text { women }(n=29)\end{array}$ \\
\hline Age (range) & $57(37-66)$ & $49(22-65)$ \\
Marital status & & \\
$\quad$ Married & 14 & 15 \\
$\quad$ Never married & 2 & 9 \\
$\quad$ Other (divorced, widowed) & 7 & 5 \\
Occupation & 10 & \\
Paid job & 2 & 12 \\
Unemployed & 4 & 1 \\
$\quad$ Disabled & 9 & 5 \\
Housewife/retired & 0 & 7 \\
$\quad$ Student & 3 & 4 \\
Highest education & 3 & 5 \\
$\quad$ Lower secondary school & 17 & 5 \\
$\quad$ Higher secondary school & & 19 \\
Post secondary school & & \\
\hline
\end{tabular}


Box 1. Quotes from women preferring explicit or general prognostic information.

If a physician says: "Madam, in your situation, with your cancer cells and your metastases - and they can infer much from that - we know that..." It would be useless to hear that I will die between 1 and 10 years from now. That's not concrete enough, so they'd better say nothing then. If they say: 'It's 3 years, give or take a year or two", yes. I do understand that they cannot say: "It will last 2 years and 4 months." They cannot say that. But at least I have some kind of indication that they have taken a look at it. That would be specific enough, but not between 1 and 10 years. (survivor, age 55)

I would like to know very explicitly. Not too vague in terms like 'some years' or 'some months'. (healthy woman, age 59)

A kind of minimum-maximum perspective. Like, if it progresses very rapidly and invasively, how long do I have then? And if I'm lucky, how long might I have? If it's 3 weeks or 3 years, well, give me some idea. (survivor, age 60)

They don't know what will happen. So, they cannot say, because they don't know. They can give a general indication: "Often when the disease has progressed like this so far, then it will be approximately so many years"; but more than that they cannot say. (healthy woman, age 26)

Perhaps some estimate. There will be degrees varying from 'this will be over next week' to 'it will take months or years'. (healthy woman, age 23) 
Vliet, L. van, Francke, A., Tomson, S., Plum, N., Wall, E. van der, Bensing, J. When cure is no option: how explicit and hopeful can information be given? A qualitative study in breast cancer. Patient Education and Counseling: 2013, 90(3), 315-322

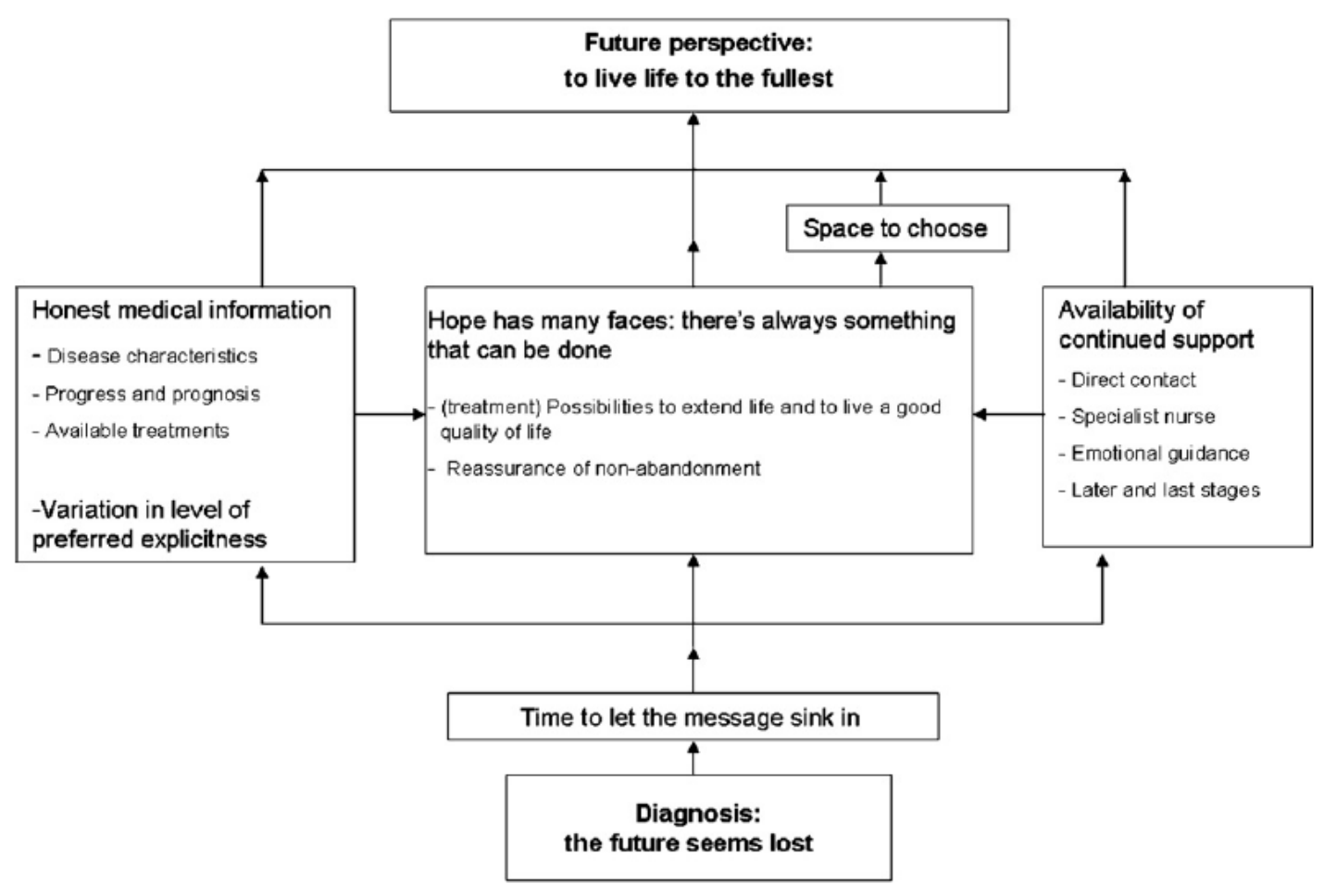

Fig. 1. Potential relationships among described themes. 